\title{
CIENCIA EN EL MADRID DEL “NO PASARÁN". LA PROTECCIÓN DE LAS COLECCIONES DE HISTORIA NATURAL Y EL INSTITUTO NACIONAL DE CIENCIAS NATURALES DURANTE LA GUERRA CIVIL
}

\author{
Francisco Pelayo \\ Departamento de Historia de la Ciencia \\ Instituto de Historia (CSIC) \\ Email:francisco.pelayo@cchs.csic.es \\ ORCID iD: http://orcid.org/0000-0002-8310-1696
}

Recibido:19 diciembre 2018; Aceptado: 11 abril 2019

\begin{abstract}
Cómo citar este artículo/Citation: Pelayo, Francisco (2019), “Ciencia en el Madrid del 'no pasarán'. La protección de las colecciones de Historia Natural y el Instituto Nacional de Ciencias Naturales durante la Guerra Civil", Asclepio, 71(2): p276. https://doi. org/10.3989/asclepio.2019.17

RESUMEN: Los edificios culturales y científicos de Madrid se vieron muy perjudicados por la guerra civil española (1936-1939). Madrid fue una ciudad asediada y bombardeada por los sublevados. En la capital se encontraban los más importantes museos, la Biblioteca Nacional y las principales instituciones científicas y de humanidades, en donde trabajaban los más relevantes investigadores de la época. A comienzos de la guerra tuvo lugar la incautación de bibliotecas y colecciones de ciencias naturales en palacios y edificios pertenecientes a aristócratas, financieros, personas contrarias a la República y colegios de religiosos. Los naturalistas del Instituto Nacional de Ciencias Naturales organizaron la conservación y protección de las colecciones biológicas, mientras que bombas y obuses impactaban en las instituciones cientificas de la zona republicana.
\end{abstract}

PALABRAS CLAVE: Colecciones científicas; Incautación de colecciones científicas; Guerra civil española; Instituto Nacional de Ciencias Naturales; Instituciones científicas bombardeadas.

SCIENCE IN NO PASARÁN MADRID. THE PROTECTION OF THE COLLECTIONS OF NATURAL HISTORY AND

Abstract: The cultural and scientific buildings of Madrid were severely damaged by the Spanish Civil War (1936-1939). Madrid was a city besieged and bombed by the rebels. In the capital were the most important museums, the National Library and the main scientific and humanities institutions, where the most important researchers of the time worked. At the beginning of the war the confiscation of libraries and collections of natural sciences took place in palaces and buildings belonging to aristocrats, financiers, people opposed to the Republic and religious schools. The naturalists of the National Institute of Natural Sciences organized the conservation and protection of the biological collections, while bombs and howitzers fell on the scientific institutions of the republican zone.

KEY WORDS: Scientific collections; Confiscation of scientific collections; Spanish Civil War; National Institute of Natural Sciences; Bombed scientific institutions.

Copyright: @ 2019 CSIC. Este es un artículo de acceso abierto distribuido bajo los términos de la licencia de uso y distribución Creative Commons Reconocimiento 4.0 Internacional (CC BY 4.0). 


\section{INTRODUCCIÓN}

Los bombardeos del Museun National d'Histoire Naturelle de Paris en enero de 1871, que ocasionaron la destrucción de plantas del invernadero y colecciones zoológicas de galerías y laboratorios (Delondre, 1871), del Royal College of Surgeons de Londres en mayo de 1941, que acabaron con una parte de la colección donada por el cirujano John Hunter, así como con algunos fósiles recolectados por Darwin en Bahía Blanca (Parker, 2011), o el del Museum für Völkerkunde de Berlín en febrero de 1945, cuyo incendio arrasó parte de los fondos de la biblioteca (Valdovinos, 2013), son algunos ejemplos de los efectos devastadores que los conflictos armados han causado en los edificios de las instituciones científicas y sobre las colecciones que conservan. Otro ejemplo de capital europea damnificada por actos bélicos es Madrid. En efecto, la rebelión contra el gobierno de la República española en 1936 y la consiguiente Guerra Civil repercutiría de forma muy perjudicial en los entornos culturales y científicos de Madrid, ciudad que fue asediada y bombardeada por los sublevados. En la capital se encontraban los más importantes museos, la Biblioteca Nacional y las principales instituciones científicas y de humanidades, integradas éstas en la Junta para Ampliación de Estudios e Investigaciones Científicas (JAE), organismo en el que trabajaban los más relevantes investigadores de la época. El agravante del bombardeo de Madrid fue que serían los propios españoles, el ejército de Franco con la ayuda de la aviación alemana, los que atentaron contra su patrimonio cultural y científico.

Las vicisitudes que rodearon a la protección del patrimonio histórico-artístico durante la Guerra Civil ha sido objeto de estudios realizados, entre otros, por Álvarez Lopera (1982 y 2009), Argerich y Ara (2009) y Saavedra Arias (2016). Menos conocido es el relato de las incautaciones y las disposiciones tomadas por las autoridades republicanas y los naturalistas de instituciones científicas madrileñas, comprometidos con la legalidad, para proteger del asedio franquista las colecciones científicas, confiscadas y públicas, y los edificios de los centros de investigación donde se custodiaban (Otero Carvajal y López Sánchez, 2012: 998, 1013,1015-1016; Aragón, 2014: 233237; Pelayo, 2016: 201-207).

Tras el inicio de la guerra, los naturalistas del Instituto Nacional de Ciencias Naturales de la JAE, constituido en torno al entomólogo Ignacio Bolívar y que permanecieron fieles a la legitimidad democrática representada por la República, se vieron obligados a adaptar su trabajo a dos nuevos factores que alteraron su labor cotidiana. El primero de ellos, y al igual que el resto de la población que vivía en el Madrid republicano, fueron las circunstancias derivadas del conflicto armado, con el peligro de caída de bombas y obuses en los centros donde realizaban su función. De hecho las tres instituciones que formaban el Instituto Nacional de Ciencias Naturales (INCN), es decir el Museo Nacional de Ciencias Naturales (MNCN), el Jardín Botánico (JB) y el Museo de Antropología (MA), serían alcanzadas por proyectiles del ejército rebelde. En este ambiente bélico tuvieron que desarrollar su actividad encaminada a la protección del patrimonio cultural. El segundo fue la reorganización administrativa y política motivadas por el desarrollo desfavorable de la guerra, con la evacuación a Valencia de la mayor parte de la plantilla, circunstancia que repercutiría intensamente en las labores investigadora y de custodia de las colecciones científicas.

\section{EL INSTITUTO NACIONAL DE CIENCIAS NATURALES (INCN)}

Ignacio Bolívar, presidente de la Junta de Profesores de los Museos de Historia Natural, propondría en la sesión del 21 de agosto de 1936 de dicha Junta designar con un nombre común, el INCN, al grupo de centros de la JAE que se dedicaban a la investigación en ciencias naturales. Este conjunto lo constituían el Museo Nacional de Ciencias Naturales (MNCN), con sus anejos la estación Alpina de Biología de Cercedilla y la Estación de Biología Marina de Marín (Pontevedra), el Jardín Botánico (JB) y el Museo de Antropología $(\mathrm{MA})^{1}$. Aunque conservaban su independencia económica y administrativa, todos se regían desde 1930 por el mismo Reglamento, el cual determinaba que su misión era el estudio de las producciones naturales de España y de las colonias y el protectorado de Marruecos$^{2}$. La propuesta de Bolívar fue ratificada al mes siguiente por el Ministerio de Instrucción Pública y Bellas Artes ${ }^{3}$.

El objetivo del INCN, tanto en Madrid como más adelante en Valencia al ser evacuada parte de la plantilla a esta ciudad, era llevar a cabo labores de tipo cultural y de carácter científico. En el primer aspecto, se quería vulgarizar la ciencia por medio de conferencias, cursillos breves sin carácter académico y exposiciones de objetos representativos y de coleccio- 
nes dispuestas para la ilustración del público, todo ello de forma gratuita. La actividad investigadora se realizaba en los laboratorios, donde los especialistas disponían para su trabajo de bibliotecas y colecciones de Historia Natural.

Los ejemplares de estas colecciones se habían ido reuniendo a lo largo de muchas décadas, desde el siglo XVIII, y muchos habían sido obtenidos en las excursiones y expediciones organizadas por las propias instituciones en territorio español o de otros países para recolectar especímenes. La incorporación de fondos se hacía, también, a través de donaciones de particulares, compras, cesiones entre centros estatales y por intercambios con otros museos y centros nacionales y extranjeros (Barreiro, 1992). De manera que al comenzar la guerra, el MNCN disponía de nutridas colecciones de zoología, tanto de invertebrados como de vertebrados, de mineralogía y paleontología, ésta última estudiadas por Montero (2002). Además, la creación de la Comisión de Investigaciones Paleontológicas y Prehistóricas (CIPP) por RR.OO. de 1912 y 1913, propició el inicio de una importante colección de copias de arte rupestre español. El JB conservaba un valioso herbario histórico fruto, entre otros, de los resultados de las expediciones científicas del siglo XVIII, acompañado de láminas y descripciones manuscritas de las plantas recogidas. Destacaban los miles de dibujos realizados por el grupo de dibujantes que había trabajado en la expedición botánica dirigida por José Celestino Mutis al Reino de Nueva Granada (1783-1816), la actual Colombia. Asimismo, el archivo del JB custodiaba las cartas que el naturalista sueco, Carl von Linné había dirigido a mediados del siglo XVIII a su discípulo Pehr Löfling, durante la estancia de éste en España y su posterior viaje al Orinoco. El MA por su parte conservaba colecciones de cráneos humanos, momias sudamericanas y guanches, las colecciones de industria paleolítica como la procedente de San Isidro, la colección prehistórica reunida en el siglo XIX por Juan Vilanova, etc. Las tres instituciones disponían en sus bibliotecas de colecciones de revistas científicas especializadas, aparte de las obras de Historia Natural de los siglos XVI al XVIII que se conservaban en el MNCN y los libros de botánica pre-linneanos del JB.

Previamente a la Guerra Civil, la estructura del MNCN contemplaba la existencia de diversas secciones, por áreas de conocimiento, cuyo responsable era de facto el catedrático de la especialidad en la Facultad de Ciencias. Así, en 1936, había ocho secciones, de Vertebrados u Osteozoología, Geología, Entomología, Mineralogía, Animales Inferiores y Moluscos, Paleontología, Geografía Física y Ecología y Laboratorios de Anatomía Microscópica, Taxidermia y Biología Experimental (Otero y López Sánchez, 2012: 609-614, 616-617). Para recolectar, ordenar, arreglar y cuidar las colecciones y colaborar en su estudio y clasificación de las especies, el MNCN disponía de un personal técnico formado por conservadores, preparadores y colectores; para el arreglo de los ejemplares de las exposiciones contaba con auxiliares artísticos, disecadores, escultores taxidermistas, a lo que había que añadir el personal de apoyo auxiliar para la biblioteca y los laboratorios. En el caso del JB esta institución contaba con jefes de Secciones de Cultivos, Herbarios y Flora Tropical, conservadores, jardineros, colectores, preparadores, ayudantes de jardineros, un auxiliar artístico y el bibliotecario (Otero y López Sánchez, 2012: 917, 1010-1011). Por su parte, el MA disponía de jefes de secciones de Antropología, Etnográfía y Prehistoria, conservadores, colectores-preparadores y personal de apoyo (Otero y López Sánchez, 2012: 1014). Los jefes de secciones de los tres centros y los de los laboratorios del MNCN formaban la "Junta de Profesores de los Museos de Historia Natural".

Al producirse la sublevación las plantillas de las tres instituciones científicas se vieron afectadas. Varios funcionarios y personas relacionadas con los Museos se alistaron a las milicias o se incorporaron a filas, tomando parte en la defensa de Madrid, en las operaciones de la sierra, luchando en El Escorial o Cercedilla. Otros, que a mediados de julio se encontraban fuera de la capital, no se presentaron a su puesto de trabajo, bien porque apoyaron el golpe o porque no regresararon para reintegrarse en sus destinos, como los directores del JB y del MA, y algunos jefes de Secciones y conservadores de las tres instituciones (Otero y López Sánchez, 2012: 993-995).

\section{CONFISCACIONES DE COLECCIONES CIENTÍFICAS Y LIBROS (JULIO DE 1936- SEPTIEMBRE DE 1937)}

Ante la insurreción militar contra la República, milicianos de los partidos y sindicatos obreros se opusieron de manera inmediata a la rebelión. Tras el fracaso del golpe, las milicias populares ocuparon en Madrid los edificios más emblemáticos de los enemigos de la República, como los palacios de la aristocracia de Medinaceli, Bailén y Liria, la Unión Mercantil, el Círculo de Bellas Artes, el Casino de Madrid, los 
talleres de periódicos monárquicos, conservadores y católicos, inmuebles de la oligarquía financiera, establecimientos y colegios de las congregaciones y órdenes religiosas, etc. ${ }^{4}$

Muchos de estos edificios guardaban colecciones particulares de importancia artística e histórica que quedaron confiscadas (Álvarez Lopera, 2009). Ante esta situación, el Ministerio de Instrucción Pública y Bellas Artes decretaría la creación de una Junta vinculada a la Dirección General de Bellas Artes que sería responsable de los objetos de arte, históricos y científicos conservados en los inmuebles ocupados, debiendo adoptar las medidas necesarias para conservarlos, trasladarlos e instalarlos provisionalmente en museos, archivos y bibliotecas estatales, donde serían expuestos para ser disfrutados por el pueblo ${ }^{5}$. Un Decreto posterior extendería el ámbito de actuación de esta Junta, llamada de Incautación y Protección del Patrimonio Artístico, abarcando la confiscación o conservación de obras, muebles e inmuebles, de interés artístico histórico o bibliográfico que corriesen peligro de destrozo, de pérdida o de deterioro por las circunstancias irregulares del momento ${ }^{6}$. Entre el material incautado en los edificios ocupados por las milicias se hallaron colecciones de objetos y ejemplares de ciencias naturales, reunidas por aristócratas, banqueros y personas que se habían significado por su oposición a la República.

Otro Decreto establecería el cierre de los establecimientos pertenecientes a las órdenes y congregaciones religiosas vinculadas con la sublevación ${ }^{7}$. Así que también fueron requisados los materiales para la docencia de la Historia Natural en colegios católicos y libros de las bibliotecas de los conventos.

Al encontrarse con un material científico especializado la Junta de Incautación se dirigió a los expertos en ciencias naturales. Se contactó con el presidente de la JAE, Ignacio Bolívar (Gomis, 1988; Puig-Samper, 2016), quien también era director del MNCN, por lo que esta institución fue la encargada de gestionar y proteger las colecciones y material de historia natural requisado. En este sentido, Bolívar dirigiría el 31 de Julio de 1936 un escrito al ciudadano encargado de la custodia del palacio de Medinaceli de Madrid, abandonado por sus dueños, informándole de los nombres de los funcionarios del Museo que estaban autorizados para hacerse cargo de la colección zoológica de dicho edificio. Los comisionados fueron un disecador del MNCN, un becario de entomología, dos preparadores de taxider- mia y dos mozos para que ayudaran al traslado de materiales y libros. A ninguna otra persona le estaba permitido retener objetos de esa colección. Debían recogerse en una lista todas las piezas a medida que se fueran sacando del palacio, firmándose a continuación la documentación de la requisa por ambas partes $^{8}$. Se conserva una lista de seis folios, "Vitrinas y ejemplares recogidos en el Palacio de Medinaceli y que han sido depositados en el Museo Nacional de Ciencias Naturales", y otra de nueve folios con los libros incautados. Ambas listas llevan los sellos de las "Milicias Obreras. Sección Motorizada del Partido Socialista. Cuartel General" y del Museo Nacional de Ciencias Naturales, y firmadas por el Jefe administrativo y responsable de las milicias, y por Bolívar, como director de la institución donde se depositaría la colección y cerca de trescientos libros $^{9}$. La relación de la colección zoológica custodiada en el MNCN durante la guerra consta de grupos de aves y mamíferos naturalizados, vitrinas con ejemplares, además de un cuadro con grabados, fotos y dibujos, álbumes, cajas y paquetes con fotos, etc $^{10}$.

Antes de la guerra la colección zoológica del Duque de Medinaceli se podía contemplar en cuatro salas del palacio (Dusmet, 1920). Estaba formada por ejemplares disecados de aves y mamíferos cazados por el aristócrata durante sus viajes por el África oriental y en regiones del círculo polar. El grupo zoológico formado por un oso polar matando a una foca y una jirafa gigante, a la que hubo que cortar treinta centímetros de cuello para que cupiera en la habitación, eran ejemplares emblemáticos de esta colección. Muchos especímenes habían sido naturalizados por la firma británica Rowland Ward Ltd. y otros por José María y Luis Benedito, taxidermistas del MNCN (Romano, 1928). El palacio, situado en la calle Génova esquina Colón, tras su incautación sería utilizado por la Asociación General de Cocineros de Madrid para dar de comer a las tropas y milicias del Frente Popular y luego como Hospital de Sangre. El duque, Luis Fernández de Córdoba y Salabert, aparte de sus intereses cinegéticos que plasmó en obras sobre caza y cetrería, había estado muy relacionado con Bolívar y el MNCN. Fue Presidente del Comité del Patronato de los Museos de Historia Natural, pertenecía a la Real Academia de Ciencias Exactas, Físicas y Naturales y a la Real Sociedad Española de Historia Natural, formando parte del Comité de la Exposición Retrospectiva de Historia Natural y de la Comisión para la Exploración y Estudio del Noroeste de África. 
En la primera sesión de la Junta de Profesores de los Museos de Historia Natural tras la sublevación militar, Bolívar expuso que el MNCN había sido invitado por la Junta de Incautación a que se hiciera cargo de objetos y libros científicos de los edificios confiscados por el Estado y las milicias. Del palacio de Medinaceli, informó, se trasladaron al Museo "92 vitrinas con mamíferos y aves, en su mayoría de gran valor científico y artístico, y un número considerable de otros objetos, como cabezas de mamíferos disecados, cuernas de rumiantes, así como también valiosos libros...". Bolívar comentó también las incautaciones en las residencias de la orden de los agustinos de las calles Columela y Valverde ${ }^{11}$.

El inventario recibido por el MNCN del convento agustino de Columela contemplaba la confiscación de libros, folletos, colecciones de lepidópteros, de hongos microscópicos y de conchas, además de dibujos e instrumental científico para laboratorios de biología, química y física. Asimismo, llegaron al MNCN cajas de mariposas de la colección del agustino Ambrosio Fernández y ejemplares de las colecciones que se destinaban a la enseñanza en el colegio del Pilar. De este último la Federación de Trabajadores de la Enseñanza, vinculada a la UGT, envió al MNCN material para la docencia de geología, mineralogía, paleontología y zoología. Había colecciones de rocas y de minerales, fósiles de mamíferos, restos paleolíticos, del neolítico y de las épocas del bronce y del hierro, instrumentos oculares y otros para recolectar insectos y lepidópteros, etc ${ }^{12}$.

A mediados de agosto de 1936 el MNCN recibió del Círculo Socialista del Oeste el material incautado del colegio de los Sagrados Corazones, formado por libros, cajas de insectos, otras con preparaciones histológicas, etc. ${ }^{13}$ Por esas fechas, el Comité Este de la Sección del Socorro Rojo Internacional, entregó al MNCN 48 cuadernos de The National Geographic Magazine y un biombo de cuatro piezas con mariposas, procedente de la Casa Urquijo y Cía, el banco del mismo nombre ${ }^{14}$.

Durante el mes de septiembre de 1936, las milicias del Batallón Pi y Margall del Partido Republicano Democrático Federal, reunieron libros y objetos de historia natural confiscados de la casa del banquero Ramiro Fernández de Villota. La relación que llegó al MNCN incluía vitrinas con aves y mamíferos, cornamentas y pieles de animales, libros y fotografías. Ese mismo mes, la Junta de Incautación entregaría al MNCN una vitrina con aves disecadas, patas y huevos, etc., del domicilio de Romualdo Céspedes y Mac Crohon $^{15}$.

A comienzos de año siguiente, Antonio Zulueta, director provisional del MNCN tras serle concedida a Bolívar una licencia oficial para ausentarse de Madrid, solicitaría a la Junta de Compras del Ministerio de la Guerra la entrega en depósito de los ejemplares zoológicos naturalizados que se encontraban en el edificio que ocupaba, los cuales por su valor científico merecían ser puestos a salvo de los riesgos de la guerra. La lista la formaban las vitrinas de un lobo y dos osos del Himalaya, un tejón naturalizado, cabezas, patas y cornamentas de rumiantes, una cabeza de faisán y unos pocos libros ${ }^{16}$. Según anotación a mano del expediente, eran ejemplares de la colección de Luis de Olivares Bruguera, vizconde de Artaza, un diplomático que había estado destinado en la India.

Las incautaciones seguirían unos meses después. Así, en septiembre de 1937, el Comisario de Vigilancia del Distrito del Congreso había confiscado en un registro una colección de insectos junto a su bibliografía. La casa era de Jorge Lauffer, naturalista de origen alemán experto en lepidópteros y coleópteros, el cual había pertenecido a diversas sociedades científicas de historia natural españolas y europeas. En 1902 fue nombrado agregado al MNCN, distinción concedida por haber donado una colección de lepidópteros. Regresó a su país en agosto de 1936 (Dusmet, 1941). Zulueta comisionó al preparador García Llorens para que trasladara la colección de insectos y libros científicos y en el MNCN terminaron más de 800 cajas de insectos y seis cajones conteniendo frascos también con insectos, junto a material para preparar y cazar ejemplares y tres armarios que contenían revistas científicas $^{17}$.

Aparte de protegerse de las bombas y obuses del ejército enemigo, la República tuvo que luchar contra la propaganda franquista y la difusión de noticias falsas que cuestionaban la labor del gobierno republicano para salvaguardar de la guerra el patrimonio cultural. Bolívar salió en defensa de las incautaciones de colecciones científicas publicando en El Socialista un artículo en el que rebatía la propaganda franquista denunciando que bibliotecas y museos habían sido desasistidos y abandonados, al tiempo que justificaba las medidas que habían permitido la protección de edificios y el rescate de obras de arte, colecciones y archivos de casas particulares. Así, decía, la creación de las Juntas de Protección e Incautación había posibilitado la recuperación de materiales escondidos, 
impidiendo que fueran destruidos por los bombardeos a los que era sometido Madrid. Bolívar hacía extensiva esta salvaguarda al ámbito científico, ya que había colecciones de objetos naturales, de algunas de las cuales se desconocía su existencia, que había que proteger para evitar su dispersión y pérdida. La Junta había facilitado la entrada en los edificios incautados por las milicias posibilitando que se recogieran objetos de interés científico que añadir a las colecciones del Estado. Las incautaciones habían seguido un meticuloso protocolo, redactándose por duplicado las listas de objetos confiscados. Selladas y firmadas por los respectivos representantes, una copia quedaba en poder de cada uno de ellos, como testimonio de la entrega y recepción de los objetos. Ejemplo de esto había sido el traslado de la colección del palacio de Medinaceli, cuyos grupos biológicos en su mayoría habían sido naturalizados por los hermanos Benedito, taxidermistas del MNCN (Aragón, 2014). Para Bolívar esta colección podía compararse en belleza y composición con las del Museo Británico ${ }^{18}$.

Esta defensa de Bolívar de las incautaciones de las colecciones científicas se publicaría también en otros periódicos, como El Pueblo (Valencia) y La Vanguardia de Barcelona. En ambos diarios incidía en que debido a la curiosidad de las milicias, que acudían en gran número para ver las colecciones científicas incautadas, se había decidido, tras acabar con el arreglo de sus fondos, abrir el MNCN al público dando así por finalizadas las vacaciones reglamentarias ${ }^{19}$.

Un relato del proceso de confiscación de colecciones científicas y su trasladado al MNCN se debe a Eugenio Morales Agacino (Viejo y Gomis, 2006). Becario del MNCN sería designado por Bolívar, junto con Dionisio Peláez Fernández, ayudante de Entomología, para la recogida de objetos naturales en los edificios incautados por el Estado, entidades sindicales y secciones obreras. En septiembre de 1936, Bolívar solicitaría a la Sociedad Madrileña de Tranvías pases para que ambos pudiesen desplazarse por el centro y alrededores de la capital y realizar su cometido ${ }^{20}$.

En sus memorias Morales Agacino comenta que la Comisión Oficial encargada de hacerse cargo de los bienes de interés cultural confiscados por las milicias populares, debía incluir los objetos pertenecientes a los tres reinos de la naturaleza, como "trofeos de caza, colecciones de insectos y libros o publicaciones relacionadas con ellos" hallados en palacios o pisos requisados para preservarlos de su destrucción. Tras ser custodiados podrían ser devueltos al final de la guerra a sus legítimos dueños o ser destinados a lo que se acordase (Morales Agacino, 1993: 78). Bolívar, decía Morales, le había extendido a él y otros un volante para llevar a cabo esta misión, que cumplieron trasladando al MNCN y salvando de su posible destrucción la colección de animales disecados que formaban el pequeño pero selecto museo del duque de Medinaceli. Morales incluía también las colecciones de trofeos del duque de Arion, del conde de Villagonzalo y del vizconde de la Armería, las colecciones de insectos de José María Dusmet y la de Lauffer, la cual contenía a su vez la de Francisco de Paula Martínez Sáez, adquirida por el naturalista alemán, y por último la formada por el agustino Ambrosio Fernández. Terminaba no recordando si había habido alguna más de valor especial (Morales Agacino, 1993: 79).

\section{INSTITUCIONES CIENTÍFICAS BOMBARDEADAS (SEPTIEMBRE 1936-SEPTIEMBRE DE 1937)}

Ante el peligro que suponía la caída de bombas y obuses, la Junta de Profesores se planteó la necesidad de proteger las colecciones científicas del propio MNCN. Bolívar alertaba de que las colecciones entomológicas eran sensibles a los bombardeos, ya que la caída de un proyectil en las proximidades del Museo, y mucho más dentro del edificio, daría lugar a un fuerte temblor que podría dañar las colecciones ${ }^{21}$. La amenaza era mayor por la existencia en el propio edificio del MNCN, el Palacio de las Artes y la Industria de los Altos del Hipódromo, de un cuartel de la Guardia Civil (Otero y López Sánchez, 2012: 619-620), que ocupaba las antiguas dependencias dejadas en 1928 por el Museo del Traje Regional e Histórico, al trasladarse éste al antiguo Hospicio.

Zulueta, presidente accidental de la Junta, convocaría a los Profesores del INCN para tomar acuerdos sobre la protección de las colecciones del MNCN y del JB. Por de pronto, una pequeña parte de los libros del MNCN había sido trasladada por la Junta de Protección del Tesoro Artístico Nacional a San Francisco el Grande. Existía asimismo la posibilidad de usar un sótano del edificio de la Escuela Normal, en el Paseo de la Castellana, para guardar lo que se estimara oportuno. Pero la Junta se decantó por no sacar nada del edificio del MNCN. Se plantearon diferentes cuestiones para resolver el problema de la protección de las colecciones científicas. Una fue la colocación de 
los libros en uno de los torreones del Museo para preservarlos de los incendios. En cuanto a las colecciones entomológicas se consideró que no debían trasladarse. Los libros, instrumentos y colecciones del Laboratorio de Biología deberían bajarse al sótano del pabellón de esta dependencia. Por otro lado, se planteó que los libros de valor y los pliegos de herbario del JB, auténticas reliquias científicas y en algunos casos históricas, no debían ser desplazados, ya que se pensaba que estarían protegidos por estar cerca del Museo del Prado, un "paraguas protector". De todas formas, se consideró conveniente dividir el herbario para evitar así su posible destrucción total ${ }^{22}$.

En noviembre de 1936 sucedió lo que se temía: bombas y obuses del ejército franquista comenzaron a caer en la capital. Los destrozos causados por la aviación y la artillería alcanzaron a edificios públicos emblemáticos de Madrid, como el Museo del Prado. El peligro aumentó con el asedio a la capital de las fuerzas de Franco, por lo que el gobierno decidió trasladarse a Valencia. Se nombró entonces una Comisión provisional delegada de la JAE para que residiera en dicha ciudad, con las atribuciones correspondientes a este organismo (Otero y López Sánchez, 2012: 979).

Ese mes cayeron bombas incendiarias en el JB. Una, tras atravesar el techo del edificio, fue a parar sobre una mesa de laboratorio. Por suerte, el fuego se había sofocado inmediatamente. Ante esto, Zulueta convocó a los miembros de la Junta de Profesores para buscar la forma de proteger el archivo histórico, los libros, las láminas botánicas de la expedición de Mutis y las colecciones científicas existentes en el JB. El personal del Jardín defendió que las colecciones no debían salir de dicha institución, asumiendo que se deberían proteger en una dependencia del edificio que ofreciera el menor peligro posible frente al deterioro o la destrucción. Pero el resto de la Junta coincidía en que había que buscar la máxima seguridad, aunque esto implicara trasladar las colecciones desde el JB a otro edificio estatal. En cualquier caso, las láminas de Mutis y los documentos más valiosos que se conservaban en el Botánico debían guardarse donde hubiera las mayores condiciones de protección, ya fuera en los propios espacios del JB o fuera en algún otro centro, como el Museo del Prado u otro que dependiera del Ministerio de Instrucción Pública y que ofreciera suficientes garantías. Se decidió que los armarios compactos que guardaban la colección de láminas de la expedición de Mutis deberían emplazarse en una dependencia sin materiales combustibles, tapiando las puertas y demás huecos mediante un pequeño muro de ladrillos, intentando evitar así sacarlos fuera de Madrid. De todas formas, Zulueta manifestaría que las láminas de Mutis, las cartas de Linneo del siglo XVIII, etc., debían llevarse a un sitio más seguro que el Botánico, como eran el Museo del Prado o el MNCN. El traslado habría de realizarse con la máxima celeridad, ante el peligro que corrían las colecciones si el Botánico era ocupado por las tropas $^{23}$.

Cinco días después, hubo que abordar la cuestión de la protección de las colecciones del Museo Antropológico. La caída de dos bombas explosivas había deshecho la puerta de entrada y una parte de la verja. Era urgente salvar los objetos más valiosos sacándolos de allí, al menos los libros, ya que las colecciones de cráneos humanos y de momias ofrecían grandes dificultades para su traslado. Zulueta comentó que la sección cultural del 5ㅇ Regimiento de Milicias había ofrecido un camión para hacer los traslados de los materiales valiosos. Con urgencia había que proceder al traslado de las colecciones, ya que la situación del edificio del MA era peligrosa por estar cerca de la estación de trenes y situado enfrente del Cerro de San Blas ${ }^{24}$, el cual estaba fuertemente militarizado debido a que estaba situado en un punto elevado y dominante. En el cerillo de San Blas se habían instalado baterías de artillería y varios acuartelamientos, entre ellos el del antiguo Instituto Cajal y el del Observatorio Astronómico, situados en el extremo suroeste del Parque del Retiro (González, 2014).

La caída de una de las bombas había roto numerosos cristales de la claraboya central del edificio del MA. Al estar en peligro las colecciones se retiraron del salón grande los ejemplares más expuestos a la humedad, colocándolos junto a los muros y en sitios resguardados de la lluvia. La biblioteca se trasladaría a un departamento más protegido del primer piso ${ }^{25}$. Se solicitó que se realizaran obras para arreglar los graves desperfectos causados por la caída de proyectiles, ya que uno de ellos había explotado en la escalinata de entrada, afectando a la conservación del edificio, a las colecciones y al material que en él se conservaban. Si no era posible abordar una reparación total del edificio que permitiera la ordenación de las colecciones y la normalización del trabajo en los laboratorios, al menos era preciso reparar algunos desperfectos, aunque fuera de manera provisional. 
Se corría el riesgo de que el inmueble se viese más afectado, lo que haría imposible salvaguardar las colecciones, especialmente porque se acercaba el invierno y con él las lluvias y posibles nevadas. A la rotura de la claraboya se unía la de las tejas de la cubierta, que ocasionaba goteras en los techos que afectaban a los salones de exposición y algunos laboratorios. Además, las filtraciones de agua provocaban desprendimientos de las molduras de las salas, ocasionando peligro para el personal, el mobiliario y las colecciones. En definitiva, la puesta a salvo de los fondos, de la biblioteca y del material de los laboratorios exigía la reparación de las zonas deterioradas, aunque fuera provisionalmente. El ministerio comisionaría a un arquitecto para que inspeccionara el estado del edificio y presentara un presupuesto de las obras que habría que realizar ${ }^{26}$.

Por su parte, en el MNCN, a mediados de 1937, los trabajos continuaban desarrollándose en los laboratorios y se mantenían abiertas al público las salas de exposiciones. Seguía preocupando la situación de las colecciones entomológicas, que se habían movido desde el sótano hasta el laboratorio del piso alto debido a la aparición de humedades. A Cándido Bolívar, secretario de la Junta, no le gustó este traslado y propuso que los fondos se llevaran a un edificio externo que se pudiera incautar o alquilar. Finalmente se decidió que la colección de ortópteros se trasladara a un chalet de Chamartín, propiedad de la familia Bolívar, y el resto de colecciones de insectos fueran al pabellón del patio, que ofrecía más protección contra los bombardeos que los laboratorios, cuyas fachadas daban al exterior. Mientras en el JB, al estar más tranquila la zona, las láminas de Mutis se habían desplazado hacia un lugar también protegido pero con ventilación ${ }^{27}$.

Al igual que el JB y el MA, el edificio del MNCN padecería destrozos causados por la munición enemiga. En julio de 1937 un proyectil de cañón explotó en el interior y otro en el exterior. Una granada "estalló en el salón de Mamíferos, rompió las lunas y cristales de numerosísimas vitrinas y de los grandes escaparates de las cabras, gorilas y vitrinas de la pared de toda la primera mitad del salón. Algunos ejemplares recibieron trozos de metralla que afortunadamente no produjeron grandes daños. Otra granada atravesó la sala pequeña de aves, yendo a estallar en uno de los sótanos y ocasionando la destrucción de tabiques, techo, etc., y de varias vitrinas conteniendo grupos biológicos" 28 .
Las salas destrozadas por las caídas de los obuses se cerraron al público, solicitándose que una pareja de guardias de seguridad protegiera el edificio, ya que las ventanas habían quedado destruidas, y para que vigilaran también el jardín y los campos de experimentación del centro, a los que acudía mucho público falto de otros lugares de esparcimiento en Madrid. Se pidió también la construcción de un refugio para los funcionarios encargados de la vigilancia de las colecciones científicas que vivían allí, cuyos alojamientos no ofrecían seguridad contra los ataques aéreos ${ }^{29}$.

Unos meses después volverían a solicitar la construcción de un refugio, para unas sesenta personas, por el peligro de bombardeos, alegando que también afectaba al Instituto Torres Quevedo, que al dedicarse a la construcción de material de guerra empleaba materias explosivas ${ }^{30}$.

Los desperfectos ocasionados en el MNCN fueron valorados por un arquitecto, quien recogía en su informe que uno de los proyectiles había entrado en el interior a través de la cubierta de cristal de los espacios dedicados a exponer animales disecados. Había explotado tras chocar contra un muro de ladrillo, derribando otros dos y rompiendo dos soportes de hierro, pero no había ocasionado daños en el material científico, ya que por suerte las colecciones de insectos se habían trasladado de sitio días antes. El que había caído en el exterior provocó que se rompieran los cristales de la planta baja y bastantes de la planta principal que daba a la fachada norte. La metralla había provocado destrozos en las paredes interiores pero de poca importancia en los animales disecados. Según el arquitecto, la construcción de cubiertas en la parte destinada a museo zoológico no ofrecía seguridad contra los bombardeos. A esto había que añadir que era muy costoso proteger el material científico, debido a la escasez de los materiales de construcción y a las condiciones especiales en que se debería ejecutar. Por el contrario, la zona del Museo dedicada a la mineralogía, que no se había visto afectada, se había reformado recientemente construyéndose muy bien, por lo que se podía proteger muy bien y de manera económica de los efectos causados por los disparos de cañón.

El arquitecto aconsejaba que se tomaran medidas para proteger las colecciones. Se debía comenzar por desalojar los ejemplares y colecciones zoológicas de gran tamaño, trasladándolas a otro edificio, como, por ejemplo, la sala de exposiciones del Círculo de 
Bellas Artes. Este inmueble ofrecía mucha seguridad para el arquitecto, debido a su construcción y orientación y además, solo había que proteger tres ventanas.

Pero desde el MNCN se decidió que no se hiciera dicho traslado por la lejanía del edificio y por estar en una zona muy batida por la artillería enemiga. Se pensó como alternativa en buscar un local en la parte alta del barrio de Salamanca, zona más segura para custodiar las colecciones de aves y mamíferos y otros fondos de las salas abiertas al público ${ }^{31}$.

El arquitecto aconsejaba que para evitar la entrada de la lluvia se tabicaran las ventanas del edificio, ya que si se sustituían por cristales podían producirse roturas por los bombardeos. Asimismo, afirmaba que era preciso proteger a los animales disecados de gran tamaño, mientras que en la zona destinada a la mineralogía el material debía disponerse en su parte baja, protegiéndose las ventanas orientadas a poniente, los techos de la vivienda del conserje y el local donde se había almacenado la biblioteca. Para llevar a cabo estas obras de protección, decía, harían falta sacos terreros, ladrillos, una camioneta para el transporte de materiales, etc., por lo que el presupuesto se elevaría a las 15.000 pesetas. Esta partida se aprobaría, utilizándose para cubrir los gastos de traslado de colecciones y las obras de protección del edificio, tales como el tapiado de varias grandes ventanas del salón y la reposición de la zona del piso superior de los laboratorios de Entomología ${ }^{32}$.

El periódico El Socialista recogería en el mes de septiembre de 1937 las medidas adoptadas para proteger el patrimonio científico de los bombardeos de la aviación y los obuses de la artillería franquista. Este periódico publicaba que uno de los centros de investigación de Madrid más dañados había sido el Instituto Cajal, parcialmente destruido por los obuses. Las labores para salvar el instrumental, el material de laboratorio y la biblioteca de este Instituto tuvieron que realizarse bajo fuego enemigo. También el personal adscrito al INCN había tenido que poner a resguardo los libros y las colecciones científicas reunidas y clasificadas durante muchos años de trabajo. Se había logrado proteger valiosas colecciones científicas, aunque esto había supuesto obviamente la ralentización provisional de las actividades de investigación ${ }^{33}$.

Unos meses después se aprobaría que varios grupos zoológicos y ejemplares disecados del MNCN fueran trasladados para su protección al Museo del Prado. En este edificio, a pesar de que había sido bombardeado, se esperaba que estuviesen mejor resguardados y más seguros ${ }^{34}$. Se enviaron desde el MNCN 69 grupos de aves y mamíferos naturalizados. De los ejemplares seleccionados para ser protegidos en la Pinacoteca, 43 pertenecían a las colecciones incautadas al duque de Medinaceli, a Olivares, a Fernández de Villota y al Vizconde Armería. Los 26 objetos restantes eran especímenes naturalizados del Estado, y pertenecían a las colecciones conservadas en el MNCN, incluyendo 8 cuadros con pájaros exóticos procedentes de las colecciones del Infante D. Sebastián. Junto a vitrinas con monos y un grupo con lagartos de Guinea, se mandó un elefante pequeño. En el Museo del Prado las 76 vitrinas que llegaron del MNCN se dispusieron en la Rotonda de entrada, en las salas Italianas y en la Rotonda del Siglo XVIII ${ }^{35}$.

\section{EL INSTITUTO NACIONAL DE CIENCIAS NATURALES EN VALENCIA (SEPTIEMBRE DE 1937-ENERO DE 1939)}

A finales del verano de 1937 el gobierno dispuso que los catedráticos y profesores de Universidad se presentaran en la Secretaría General de la Universidad de Valencia, para empezar en octubre el curso y que los departamentos ministeriales debieran comunicar la relación del personal indispensable que permanecerían prestando servicio en Madrid. El resto de los funcionarios debían desplazarse a los destinos que se les encomendasen o, en su defecto, a Valencia ${ }^{36}$. Esta evacuación de empleados públicos afectaba a los docentes universitarios y a la plantilla formada por investigadores, personal técnico y de apoyo del MNCN y el JB.

Los días 25 y 26 de septiembre de 1937, en el Hotel Victoria de Valencia se reunió la Junta Directiva de los Museos de Ciencias Naturales y Jardín Botánico, bajo la presidencia de Bolívar. Se abordó la organización del INCN y la necesidad de cubrir los cargos de directores del JB y del MA, vacantes por las ausencias de sus titulares. Fueron nombrados José Cuatrecasas para la dirección del Jardín y José Royo Gómez para la del Antropológico. El primero de ellos recordó los destrozos causados en el Botánico por los diversos bombardeos, que por suerte no habían afectado a las colecciones científicas ni a la biblioteca, reponiéndose los numerosos cristales rotos. Respecto a la colección de láminas de la expedición de Mutis ma- 
nifestó que, pese a que se habían extremado las medidas de seguridad, seguían estando en peligro, por lo que era conveniente que se trasladaran a una de las cámaras blindadas que se habían construido en Valencia, donde se podían conservar resguardados en perfectas condiciones cuadros y obras de arte. Se acordó que Cuatrecasas se encargara de que se llevara a cabo el traslado de dicha colección de láminas a Valencia, con las condiciones de máxima seguridad, tal como había ordenado la Dirección General de Bellas Artes. Al día siguiente la Junta abordó la disposición sobre el personal de los tres centros que debía ser evacuado, decidiéndose que en Madrid sólo quedara el personal mínimo indispensable para la vigilancia y cuidado de las colecciones. Así, en el MNCN, se decidió que Zulueta junto con Luis Crespí, el taxidermista Luis Benedito y algunos preparadores, colectores, un guardia de seguridad y subalternos, quedaran en Madrid. También quedaría en la región central el colector Jerónimo Hernández, al que se le había confiado desde el comienzo de la sublevación la custodia de la Estación Alpina de Biología. A Valencia sería trasladado el resto del personal junto con el material científico, libros y enseres ${ }^{37}$. Relaciones de nombres parecidas se hicieron en el JB, decidiéndose que en la capital quedaran Cuatrecasas como director que alternaría su estancia entre Madrid y Valencia, junto con un preparador, un auxiliar artístico, un bibliotecario y un ordenanza de la Biblioteca, un auxiliar subalterno y varios jardineros y ayudantes de jardinería. Del MA deberían quedar en Madrid Royo Gómez, que como director alternaría su estancia entre la capital y Valencia, y los colectores preparadores Juan Cabré y Antonio Cruz Collado junto con los auxiliares ${ }^{38}$.

Durante el mes de octubre de 1937, entre el 18 y el 24, la Junta de Profesores se reuniría en cuatro ocasiones en el edificio de la Presidencia de la República de Valencia. Se continuó discutiendo sobre las mejores condiciones de seguridad para las colecciones custodiadas en los edificios de Madrid pertenecientes al INCN. Por una parte, se deseaba trasladar los ejemplares de las colecciones científicas y guardarlas en lugares seguros, pero por otra, había consciencia de que muchos ejemplares sufrirían daños en la operación de traslado. Tuvieron que tomarse medidas para evitar el deterioro causado por goteras en la sala de paleontología, trasladándose el depósito de publicaciones de la revista "Eos", que estaba en el antiguo salón del Diplodocus. Algunos de los ejemplares de esta revista estaban deteriorados, no porque se hubieran mojado sino debido a la explosión de la granada que había entrado en los sótanos. Se ordenó poner tiras de papel engomado en los cristales de los laboratorios y vitrinas para reducir en lo posible los efectos de los bombardeos. Mientras en Valencia, tras visitar varios locales, se decidió que los laboratorios y archivos del INCN se trasladaron al edificio del Hospital de Sacerdotes Pobres ${ }^{39}$.

Cuatrecasas cumpliría lo acordado por la Junta de Profesores y así, en el JB de Madrid se realizó un inventario de las cuarenta y dos carpetas y un tomo encuadernado en que estaban distribuidas las láminas de la Flora de Nueva Granada de Mutis. En total eran 3.042 láminas de tamaño folio en color, 1.067 a medio folio también en color, 2.520 en negro y quince folios manuscritos ${ }^{40}$. Así que se levantó acta de la entrega a la Junta Delegada del Tesoro Artístico de las cajas de madera con las estampas de la colección botánica de Mutis, disponiendo la Dirección General de Bellas Artes que se trasladaran a Valencia y se depositaran en sitio seguro ${ }^{41}$. De Madrid saldrían junto a otros objetos de arte del Museo del Prado. Los siete cajones con las láminas de la expedición Mutis volverían, tras pasar por Valencia, Barcelona y Ginebra, al Jardín Botánico en junio de $1939^{42}$ (Balguerías, 1954: 116-117).

A mediados de enero de 1938, la llegada a Valencia de muebles, libros y material científico procedentes de Madrid posibilitó continuar las investigaciones científicas en el INCN. Los naturalistas desplazados a Valencia redactaron un plan de trabajo. Éste contemplaba estudios de criptogamia, especialmente de las algas, actividades de pescas periódicas de la fauna ictiológica del litoral mediterráneo y de sus albuferas y marismas, estudios de herpetología, de la fauna malacológica terrestre y lacustre y de la avifauna de la región, especialmente de la Albufera de Valencia. Para esto último se consiguió un permiso del ayuntamiento a fin de que el preparador Bernaldo de Quirós pudiera cazar ejemplares. Asimismo, se consideró emprender investigaciones en yacimientos mineralógicos y paleontológicos. El objetivo era recoger ejemplares y objetos naturales para aumentar las colecciones de los centros nacionales. En cambio, no se había podido conseguir el vaciado de los fósiles del Museo Paleontológico Rodrigo Botet de Valencia. Tras haber caído una bomba cerca de este museo, rompiendo los cristales de la fachada del edificio (Salinas, 2001: 215-222), se decidió que los ejemplares 
más importantes se desmontaran, empaquetaran y encerraran en cajones, conservándose en lugar seguro para preservarlos de los bombardeos, los cuales se intensificaron a partir de junio de 1938 (Catalá, Belinchón y Acosta, 2017: 57).

Pero en Valencia también se preocupaban de la situación en Madrid. Así, en la sesión celebrada el 17 de Enero de 1938 en los laboratorios del Instituto de Ciencias en Valencia, la Junta abordaría las actividades desarrolladas en Madrid para salvaguardar el estado de las colecciones. Así respecto al MA, Royo Gómez comentaría que ante la falta de uralita que había impedido realizar las obras de reparación necesarias, se pensó en construir cajas para que las momias americanas no sufrieran deterioro y pudieran ser trasladadas al Museo del Prado, donde estarían protegidas de los bombardeos. Se abordó también que en el JB había habido otros desperfectos en la verja ocasionados por una granada enemiga y tampoco se habían podido emprender las obras proyectadas debido a la falta de cemento en la capital. Cuatrecasas informó que el personal del JB que permanecía en Madrid estaba encargado de conservar, arreglar y ordenar el herbario e indicó la necesidad de hacer las gestiones necesarias para recoger del Instituto de Teruel el herbario de Francisco Loscos y José Pardo. También se habían hecho trámites para integrar en las colecciones estatales el herbario y la biblioteca de Carlos Pau. Asimismo, Cándido Bolívar comentó en la reunión la conveniencia de visitar en Madrid las casas de Eduardo Hernández Pacheco, Hugo Obermaier y Julio Martínez de Santa-Olalla. Los dos primeros era jefes de sección en el MNCN y en el MA respectivamente al estallar la sublevación y el tercero, profesor auxiliar universitario y militante de Falange. En los domicilios de estos ausentes de sus puestos de trabajo había libros y materiales pertenecientes a los centros dependientes del INCN que era necesario recuperar para que no se extraviasen ${ }^{43}$.

Ya desde los primeros meses de 1938, con la guerra decantándose a favor de los sublevados, parte del INCN salió de Valencia hacia Barcelona, acompañando al gobierno republicano. Entre finales de 1938 y comienzos de 1939, se irían dando órdenes para el regreso a Madrid de forma escalonada del resto de la plantilla, devolviéndose al MNCN la mayor parte del material enviado a Valencia, ya que otros objetos retornaron tras terminar la guerra (Otero y López Sánchez, 2012: 1006-1008).

\section{EPÍLOGO: EL FINAL DEL INSTITUTO NACIONAL DE CIENCIAS NATURALES Y LA DEVOLUCIÓN DE LAS COLECCIONES INCAUTADAS (1939).}

El regreso a Madrid de los naturalistas destinados en Valencia fue el final de la reestructuración del INCN, que había implicado la separación del personal científico y de apoyo y una división de las actividades que pasaron a realizarse en dos ciudades. La causa de la vuelta a Madrid fue la inminente pérdida de la guerra por parte de la República. Esta separación forzada por las circunstancias había tenido lugar en el peor momento, ya que las plantillas de los tres centros que formaban el INCN habían disminuido tras el estallido de la guerra. Así, en el trabajo científico a tiempo completo no podían dedicarse los que ejercían cargos de responsabilidades política, como, por ejemplo, Cándido Bolívar, Secretario de la Casa de la Presidencia con Azaña, Royo Gómez que fue Director General de Minas y Vicesecretario de la JAE, o Enrique Rioja, con puestos en el ámbito educativo. Por otro lado, faltaban los que se habían incorporado al frente o unido a las milicias, los que se ausentaron de su puesto de trabajo por estar a favor del golpe de Estado y los que por distintos motivos en el momento de la sublevación se encontraban fuera de Madrid y no regresaron a la capital. Con la reestructuración impuesta por directrices gubernamentales, solo una parte del personal del INCN, aquellos cuya su presencia era imprescindible para custodiar las colecciones y bibliotecas y cuidar de las plantaciones del JB, había permanecido en las instituciones científicas de la capital, mientras que el resto fue evacuado, junto con materiales, enseres y libros, hacia Valencia, sede de la administración republicana, donde continuarían con sus trabajos. En esta situación, tan extemporánea para la actividad científica al estar mediatizada por la política y la guerra, los naturalistas republicanos tuvieron que proteger las colecciones y desarrollar su labor investigadora. Resulta evidente lo difícil que tuvo que ser su labor.

La derrota de la República en 1939 fue seguida por la marcha al exilio del núcleo del INCN con responsabilidades políticas, como los Bolívar, Royo Gómez o Rioja. Al mismo tiempo en España comenzaron los procesos de depuración del personal del INCN que se había quedado en zona republicana (Otero y López Sánchez, 2012: 1081-1114). El comisionado para informar sobre las depuraciones del personal del INCN fue el presbítero Filiberto Díaz Tosaos, antiguo conservador de Mineralogía del MNCN. En su biografía 
se recoge que, a pesar de estar jubilado, a solicitud del director provisional, había acudido en diciembre de 1936, con el consiguiente riesgo físico, al MNCN para salvaguardar las colecciones mineralógicas propiedad del Estado, seriamente amenazadas por los bombardeos. Además, su biógrafo atribuía a Díaz Tosaos la incautación de la colección entomológica de Lauffer, abandonada en un piso evacuado, haciéndola transportar intacta al MNCN. En prueba de su agradecimiento, los herederos de Lauffer la habían donado al Museo (García Bayón, 1945: 184).

Díaz Tosaos fue el encargado de contactar con los antiguos dueños de los objetos y colecciones científicas incautadas durante la guerra y depositadas en el MNCN. Así, en mayo de 1939, durante los pocos días en que ocupó la dirección del MNCN, Díaz Tosaos dirigió un escrito al duque de Medinaceli, a Fernández de Villota, a Luis de Olivares, al vizconde de la Armería, a los Urquijo, al agustino Luis de Unamuno, un micólogo vinculado al JB que residía en el convento de los agustinos de la calle Columela, al superior del colegio de los Sagrados Corazones, al director del colegio del Pilar y a los jesuitas del colegio de Nuestra Señora del Recuerdo de Chamartín, indicándoles que el MNCN tenía a su disposición los objetos de su pro-

\section{NOTAS}

1 Archivo del Museo Nacional de Ciencias Naturales (AMNCN), ACN0311/002, Libro de Actas de las Sesiones celebradas por la Junta de Profesores de los Museos de Historia Natural (Museo Nacional de Ciencias Naturales, Jardín Botánico y Museo de Antropología), p. 91.

2 Reglamento de los Museos Nacional de Ciencias Naturales, Antropológico y Jardín Botánico, aprobado por Real Orden de 25 de Septiembre de 1930.

3 Gaceta de Madrid, n. 246, 2 de Septiembre de 1936.

4 El Liberal, 23 de Julio de 1936, p. 4; La Libertad, 24 de Julio de 1936, p. 4; Ahora, 24 de Julio de 1936, p. 9.

5 Gaceta de Madrid, n. 207, 25 Julio 1936, p. 834.

6 Gaceta de Madrid, n. 215, 2 Agosto 1936, p. 999.

7 Gaceta de Madrid, n. 226, 13 Agosto 1936, pp. 1222-1223.

8 AMNCN, ACN0279/016, Expediente sobre la incautación de colecciones durante la Guerra Civil Española con destino al Museo Nacional de Ciencias Naturales, Doc. 3.

9 AMNCN, ACN 0279/016, Expediente sobre la incautación..., Doc. 5, Doc. 6.

10 AMNCN, ACN 0279/016, Expediente sobre la incautación..., Doc. 9. piedad que habían sido incautados. Les pedía que a la mayor brevedad posible indicaran cuándo pensaban pasarse para recogerlos ${ }^{44}$. Hay constancia en el Archivo del MNCN de que fueron recuperados por sus propietarios los objetos confiscados de Fernández de Villota, Romualdo Céspedes, el conde de Villagonzalo ${ }^{45}$ y el duque de Medinaceli. Este último indicó en noviembre de 1939 que tenía el propósito de reinstalar en su palacio los grupos zoológicos depositados en el Museo ${ }^{46}$.

Con la devolución de las colecciones científicas y bibliotecas terminaría la labor de custodia y protección del patrimonio que realizaron los naturalistas republicanos del INCN en un Madrid asediado y bombardeado durante la Guerra Civil.

\section{AGRADECIMIENTOS}

Trabajo realizado en el proyecto de investigación: "El coleccionismo científico y las representaciones museográficas de la Naturaleza y de la Humanidad", financiado por la Agencia Estatal de Investigación del Gobierno de España y el Fondo Europeo de Desarrollo regional (HAR2016-75331-P.AEI/FEDER, UE).
11 AMNCN, ACN0311/002, Libro de Actas de las Sesiones celebradas por la Junta de Profesores de los Museos de Historia Natural (Museo Nacional de Ciencias Naturales, Jardín Botánico y Museo de Antropología), Sesión del 21 de Agosto de 1936, p. 90.

12 AMNCN, ACN0279/016, Expediente sobre la incautación..., Docs. $10-14$

13 AMNCN, ACN0279/016, Expediente sobre la incautación..., Doc. 16.

14 AMNCN, ACN0279/016, Expediente sobre la incautación..., Doc. 15.

15 AMNCN, ACN0279/016, Expediente sobre la incautación..., Doc. 19 y 21.

16 AMNCN, ACN0279/019, Expediente por el que los ejemplares zoológicos depositados en el edificio que ocupa la Junta de Compras del Ministerio de la Guerra son enviados al Museo de Ciencias para ponerlos a salvo de la guerra, 1937-01-23/1937-05-16.

17 AMNCN, ACN0279/023, Expediente por el que el Museo de Ciencias, de acuerdo con el Comisario de Vigilancia del Distrito del Congreso de Madrid, recoge una colección de insectos y bibliografía encontrados durante el registro de la habitación de Jorge Lauffer, 1937-09-13/1937-10-01. 
18 Bolívar, Ignacio: "Cultura Española. Se han salvado y se conservan colecciones de gran valor en Ciencias Naturales", El Socialista, n. 8556, 29 de agosto de 1937, p. 4.

19 Bolívar, Ignacio: "Unas cuartillas del sabio naturalista español don Ignacio Bolívar Urrutia, director del Museo Nacional de Ciencia Naturales ¿Quiénes son los amantes de la cultura?", El Pueblo, 29 de agosto de 1937, p. 5; Bolívar, Ignacio: “¿Quiénes son los amantes de la cultura?", La Vanguardia, 12 de septiembre de 1937.

20 AMNCN, Fondo Museo, Serie Administración, caja 1019.

21 AMNCN, CN0311/002, Libro de Actas de las Sesiones celebradas por la Junta..., Sesión del 10 de Septiembre de 1936, p. 93.

22 AMNCN, CN0311/002, Libro de Actas de las Sesiones celebradas por la Junta..., Sesión del 12 de Noviembre de 1936, pp. 94-95.

23 AMNCN, CN0311/002, Libro de Actas de las Sesiones celebradas por la Junta..., Sesión del 20 de Noviembre de 1936, pp. 95-97.

24 AMNCN, CN0311/002, Libro de Actas de las Sesiones celebradas por la Junta..., Sesión del 25 de Noviembre de 1936, pp. 98-100.

25 AMNCN, CN0311/002, Libro de Actas de las Sesiones celebradas por la Junta..., Sesión del 15 de mayo de 1937, p. 102.

26 Archivo de la JAE, Expediente Museo de Antropología en Madrid, 162/289, Residencia de Estudiantes, Madrid.

27 AMNCN, CN0311/002, Libro de Actas de las Sesiones celebradas por la Junta..., Sesión del 12 de Junio de 1937, pp. 104-106.

28 AMNCN, Serie Administración, Caja 1019, Carp. 06, Junta Directiva de los Museos de Ciencias Naturales y Jardín Botánico, Sesiones del 25 y 26 de Septiembre de 1937.

29 AMNCN, Serie Administración, Caja 1022, 24 de Junio de 1937 y 15 de Julio 1937.

30 AMNCN, ACN0315/005/001, 29 Noviembre de 1937

31 AMNCN, Serie Administración, Caja 1019, Carp. 06.

\section{BIBLIOGRAFÍA}

Álvarez Lopera, José (1982), La política de bienes culturales del gobierno republicano durante la guerra civil española, Madrid, Ministerio de Cultura.

Álvarez Lopera, José (2009), "La Junta del Tesoro Artístico de Madrid y la protección del patrimonio durante la Guerra Civil". En: Isabel Argerich y Judith Ara (eds.), Arte protegido. Memoria de la Junta del Tesoro Artístico durante la Guerra Civil, Madrid, Ministerio de Cultura, 2009, pp. 27-28.

Aragón Albillos, Santiago (2014), En la piel de un animal. El Museo Nacional de Ciencias Naturales y sus colecciones de Taxidermia, Aranjuez, Doce Calles /CSIC.
32 AMNCN, ACN0315/006/001, Informe del arquitecto Vicente Eced Eced sobre los daños sufridos por el Museo después de la explosión de dos proyectiles..., 12-19 Julio de 1937.

33 "Mientras ellos destruyen. Las Instituciones culturales que ha salvado la República". El Socialista del 10 de septiembre de 1937.

34 AMNCN, ACN0279/025, Expediente por el que el Museo Nacional de Ciencias Naturales entrega ejemplares de aves y mamíferos al Museo del Prado para que los custodie durante la guerra, 1937-12-20 / 1938-06-17.

35 Archivo del Museo del Prado (AMP), Caja 1000, Leg. 11.235, Exp. n. 1, 20 de Diciembre de 1937.

36 Gaceta de la República, n. 243, 31 de Agosto 1937, p. 875 y Gaceta de la República, n. 252, 9 de Septiembre 1937, pp. 991-992.

37 AMNCN, ACN0352/011/003 Expediente de traslación de personal del Museo Nacional de Ciencias Naturales a Valencia, por Orden del Ministerio de Instrucción Pública y Bellas Artes, 1937-09-25/1938-10-16.

38 AMNCN, Serie Administración, Caja 1019, Carp. 06, Juntas Directivas de los Museos de Ciencias naturales y Jardín Botánico, Sesiones del 25 y 26 de septiembre 1937.

39 AMNCN, Serie Administración, Caja 1019, Carp. 06, Sesiones del 18, 19, 21 y 24 de Octubre de 1937.

40 AMNCN, Serie Administración, Caja 1019, Carp. 06.

41 Archivo del Museo del Prado (AMP), Caja 135, Exp. N. 1, Doc. 84

42 AHRJB, División I, Fondo contemporáneo, Dirección del Jardín Botánico, caja 105, expediente 105/24.

43 AMNCN, Serie Administración, Caja 1019, Carp. 06, Sesión del 17 de Enero de 1938.

44 AMNCN, ACN0279/016, Expediente sobre la incautación..., Doc. 1.

45 AMNCN, ACN0279/033, 2 Diciembre 1939.

46 AMNCN, ACN0279/016, Expediente sobre la incautación..., Doc. 7.

Argerich, Isabel; Ara, Judith (2009), Arte Protegido. Memoria de la Junta del tesoro Artístico durante la Guerra Civil, Madrid, Instituto de Patrimonio Histórico Español, Museo Nacional del Prado.

Balguerías, Eduardo (1954), La Real Expedición Botánica del Nuevo Reino de Granada, Madrid, Ediciones de Cultura Hispánica, t. I, pp. 116-117.

Barreiro, Agustín J. (1992), El Museo Nacional de Ciencias Naturales, Aranjuez, Doce Calles.

Catalá Gorgues, Ignacio Jesús; Belinchón García, Margarita y Acosta Rizo, Carlos (2017), Royo Gómez. Ciència i Guerra 
en València, capital de la República, València, Ajuntament de València, Museu de Ciències Naturals.

Delondre, Augustin (1871), "Rapport sur le dégats causes au Muséum d'Histoire Naturelle de Paris par les obus de l'armée allemande pendant le bombardement de Paris en janvier 1871", Bulletin de la Socieété Botanique de Paris, t. Dix-huitième, pp. 9-16.

Dusmet Alonso, José María (1920), "Visita de la Sociedad Española de Excursiones al Palacio de los Duques de Medinaceli. La colección zoológica", Boletín de la Sociedad Española de Excursiones, XXVIII, pp. 54-56.

Dusmet, Alonso, José María (1941), “Excmo. Sr. D. Jorge Lauffer", Boletín de la Real Sociedad Española de Historia Natural, XXXIX, pp. 197-199.

García Bayón (1945), “Rvdo. P. D. Filiberto Díaz Tosaos (18661945)", Boletín de la Real Sociedad Española de Historia Natural, XLIII, pp. 179-185.

Gomis Blanco, Alberto (Presentación) (1988), “Presentación”. En: Ignacio Bolívar y las ciencias naturales en España, Madrid, CSIC, pp. VIII-XV.

González, Manuel de Vicente (2014), Fuentes primarias, documentales y gráficas para una historia militar de la Guerra Civil en Madrid, Madrid, Ministerio de Defensa, p. 95.

Montero Bastarreche, Ángel (2002), La paleontología y sus colecciones desde el Real Gabinete de Historia Natural al Museo Nacional de Ciencias Naturales, Madrid, CSIC.

Morales Agacino, Eugenio (1993). Memorias de un español de a pie. Primera parte 1914-1939, Madrid, 1993. Edición de reprografía.

Otero Carvajal, Luis Enrique; López Sánchez, José María (2012), La lucha por la modernidad. Las ciencias naturales y la Junta para Ampliación de Estudios, Madrid, Publicaciones de la Residencia de Estudiantes - CSIC.
Parker, Tabatha (2011), "Royal College of Surgeons, Lincoln's Inn Fields", West End at War: history, photos, memories, and maps of London during the Second World War, http:// www.westendatwar.org.uk/page_id_177.aspx (Consultado el 18 Octubre 2018).

Pelayo, Francisco (2016), "Los naturalistas republicanos y la protección del patrimonio científico durante la Guerra Civil". En: Murga Castro, Idoia y López Sánchez, José María (eds.), Política cultural de la Segunda República española, Madrid, Fundación Pablo Iglesias, pp. 199-221.

Puig-Samper Mulero, Miguel Ángel (2016). Ignacio Bolívar Urrutia. Patriarca de las Ciencias Naturales en España y fundador de la revista Ciencia en México. Discurso leído ante la Academia Mexicana de Ciencias, Ciudad de México, Facultad de Ciencias de la UNAM.

Romano, Julio (1928), "En el Palacio de los duques de Medinaceli. La caza del oso en los hielos del Polo Norte y la del león y la pantera en los bosques del África Oriental", La Esfera, n. 764, 25 Agosto, pp. 31-34.

Saavedra Arias, Rebeca (2016), Destruir y proteger. El patrimonio histórico-artístico durante la Guerra Civil (1936-1939), Santander, Ediciones de la Universidad de Cantabria.

Salinas Jaques, Amparo (2001), Las colecciones paleontológica y conquiológica del Museo Paleontológico J. Rodrigo Botet de Valencia: Inventario faunístico, importancia científica, museística e histórica, Valencia, Tesis Doctoral, pp. 215-222.

Valdovinos, Margarita (2013), “Las dinámicas de clasificación y exposición de las colecciones etnográficas en el Museo Etnológico de Berlín, a través de algunos ejemplos", Journal de la Société des Américanistes, 99-2, pp. 165-196.

Viejo Montesinos, José Luis; Alberto Gomis Blanco (coord.) (2006), Eugenio Morales Agacino (1914-2002): un naturalista español del siglo XX. Madrid, Universidad Autónoma de Madrid. 